
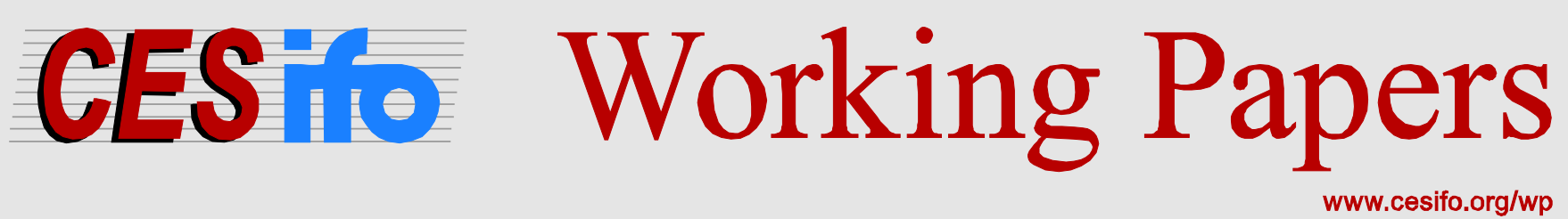

\title{
Voluntary Disclosure Schemes for Offshore Tax Evasion: An Analysis
}

\author{
Matthew Gould \\ Matthew D. Rablen
}

CESIFO WORKING PAPER NO. 5750

CATEgORY 1: Public FinANCE

FEBRUARY 2016

An electronic version of the paper may be downloaded

- from the SSRN website: Www.SSRN.com

- from the RePEc website: Www.RePEc.org

- from the CESifo website: www.CESifo-group.org/wp 


\title{
Voluntary Disclosure Schemes for Offshore Tax Evasion: An Analysis
}

\begin{abstract}
In recent years tax authorities worldwide have implemented voluntary disclosure schemes to recover tax on offshore investments. Such Schemes are characterized by the acquisition of nonaudit information on offshore holdings, and a subsequent opportunity for affected taxpayers to make a voluntary disclosure. Accepted disclosures are subject to a discounted .ne rate, but verified under-disclosure attracts a higher penalty. We characterize the optimal Scheme and show that an optimal Scheme can generate a Pareto-improvement over the optimal auditing equilibrium without a Scheme, and can stimulate legitimate offshore investment activity. We show when a tax authority optimally gives incentives for truthful disclosure, and when it does not. The analysis yields practical design insights for policymakers.
\end{abstract}

JEL-codes: H260, D850.

Keywords: voluntary disclosure, offshore tax evasion, tax amnesty, third-party information.

\author{
Matthew Gould \\ Westminster Business School \\ University of Westminster \\ 35 Marylebone Road \\ United Kingdom - London, NW1 5LS \\ gouldma@westminster.ac.uk
}

\author{
Matthew D. Rablen \\ Department of Economics and Finance \\ Brunel University London \\ Uxbridge \\ United Kingdom - Middlesex, UB8 3PH \\ matthew.rablen@brunel.ac.uk
}

February 2, 2016

We are grateful to participants at the International Tax Analysis Conference for very helpful comments. Rablen gratefully acknowledges financial support from the ESRC and HMRC (ES/K001744/1). For information relating to IOVDS in various countries we thank Rohan Baxter (Australia), Duncan Cleary and Aisling Haughey (Ireland), Kurt Norell (Sweden) and Kim Bloomquist (United States). The views expressed are ours and cannot be attributed to H.M. Revenue and Customs or H.M. Government. 


\section{Introduction}

An estimated eight per cent of the global wealth of households is held in tax havens, threequarters of which goes unreported (Zucman, 2013). The loss of tax receipts due to offshore tax evasion by individuals for the US alone has been estimated as USD 30-40 billion per annum (Gravelle, 2009). In recent years tax authorities around the world have sought to recover tax on offshore funds with a form of enforcement that may be broadly characterized as follows. First, the tax authority acquires (non-audit) information on the offshore assets of a set of taxpayers. Second, the tax authority offers affected taxpayers a one-off and time-limited opportunity to make a voluntary disclosure through a facility giving overt incentives for honesty (usually in the form of a lower fine rate). We term schemes of this form Incentivized Offshore Voluntary Disclosure Schemes (IOVDS).

Tax authorities have exploited various means of acquiring non-audit information on offshore holdings. First, they have aggressively exploited legal powers that impel financial organizations to reveal tax-related information. One of the first IOVDS, the 2007 Offshore Disclosure Facility (ODF), was implemented in the UK following legal action by the tax authority to force five major UK banks to disclose details of the offshore accounts held by their customers. The ODF offered affected taxpayers time-limited access to a reduced ten per cent fine rate if they made a full disclosure. Ireland (2004) and Australia (2009) have also implemented Schemes following similar legal action.

Second, tax authorities have cooperated with whistleblowers. In 2009 the IRS learned details of the offshore accounts of a number of US citizens with the Swiss bank UBS. It launched the Offshore Voluntary Disclosure Program (OVDP) in the same year and later implemented the Offshore Voluntary Disclosure Initiative in 2011. ${ }^{1}$ The UK implemented two Schemes the New Disclosure Opportunity and the Liechtenstein Disclosure Facility - in response to information relating to (i) $100 \mathrm{UK}$ citizens with funds in Liechtenstein; and (ii) all British clients of HSBC in Jersey (Watt et al., 2012). A list of offshore account holders of HSBC's Geneva branch - seized by French police in 2009 - is still the subject of investigation by tax authorities worldwide, as is a further list published in Center for Public Integrity (2013). ${ }^{2}$ Italy, France, Canada and Hungary are also known to have implemented disclosure schemes in response to information acquisitions (OECD, 2010). ${ }^{3}$

\footnotetext{
${ }^{1}$ See Table 1 and Appendix II of GAO (2013) for a full account of the background to, and operation of, these two Schemes.

${ }^{2}$ A sub-set of the former list is the so-called "Lagarde List" - which contains 1,991 names of Greeks with accounts in Switzerland. It was passed to the Greek authorities in 2010 by the then French Finance Minister, Christine Lagarde (Boesler, 2012).

${ }^{3}$ Some tax authorities have utilised standing (rather than bespoke) mechanisms for voluntary disclosure. In particular, Germany has not to date implemented an IOVDS, but is thought to have raised around $€ 4$ billion (OECD, 2010) in voluntary disclosures following a series of data acquisitions from citizens of Liechtenstein. In this paper we analyse only the optimal design of a bespoke Scheme in relation to a specific acquisition of offshore information, rather than the optimal design of a standing mechanism for voluntary disclosure.
} 
Third, tax authorities have exploited information arising from new legislation, such as occurred around the 2003 European Savings Directive (European Union, 2003). Last, tax authorities have taken steps to improve international cooperation through the signing of tax information exchange agreements, with the G20 countries leading in this regard. ${ }^{4}$ The creation in 2013 of an OECD Common Reporting Standard (OECD, 2013) and the 2010 Foreign Account Tax Compliance Act passed in the US are leading to continuing information flows regarding offshore investments.

The net revenues arising from IOVDS have been significant: the 2009 OVDP in the US raised some USD 3.4 billion (GAO, 2013), while in the UK the 2009 ODF raised nearly $£ 500$ million (Treasury Committee, 2012: 14). The ODF is estimated to have cost $£ 6$ million to administer (Committee of Public Accounts, 2008: 9), implying a return of $£ 67$ for every $£ 1$ spent. This compares favorably with reported yield/cost ratios in the UK of around eightto-one for traditional audit-based enforcement programs (HMRC, 2006). ${ }^{5}$ Moreover, such Schemes typically raise revenue faster than do approaches relying on (often lengthy) audits. Yet, in offering incentives for voluntary disclosure, incentivized schemes might encourage illegal offshore evasion in the first place.

To our knowledge, little systematic is yet understood concerning the predictions of economic theory for the effects of IOVDS, and their optimal design. ${ }^{6}$ Given that such Schemes are now widely in use, this seems an important lacuna. Some open questions in this context are: what considerations inform the optimal setting of the incentivized fine rate (if indeed this should be incentivized at all)?; what is the nature of optimal auditing both inside and outside of a Scheme?; and do IOVDS increase net revenue when taking into account their impact on their incentives for taxpayers to invest offshore illegally in the first place? Moreover, harking to Becker (1968) and Kolm (1973), the conventional wisdom of the economics of crime literature is that penalties should be maximal (and the probability of detection minimal). It is therefore of interest to understand when the tax authority will wish to offer a fine rate lower than the maximum allowed by legislation.

In this paper we analyze IOVDS using game theoretic tools. An important consideration at the heart of our model is that there can be legitimate economic reasons for holding money in offshore accounts. As well as enabling investors to potentially achieve higher rates of interest than available in their domestic country, offshore providers are known to offer greater convenience and sophistication, presumably as they face lighter regulatory controls

\footnotetext{
${ }^{4}$ Within eight months of the G20 summit of April 2009 tax havens had signed more than 300 treaties (Johannesen and Zucman, 2014). The UK has conducted several recent IOVDS using information obtained in this way. These include the 2009 Liechtenstein Disclosure Facility, and three Schemes aimed at its dependencies The Isle of Man, Jersey and Guernsey.

${ }^{5}$ The ratio of 8:1 is based on the estimated yield/cost ratio for self-assessment non-business enquiry work in 2005-06 of 7.8-to-one.

${ }^{6} \mathrm{~A}$ recent working paper (Langenmayr, 2015) presents an empirical analysis of the effects of the 2009 OVDP in the United States alongside a simple model. We discuss this empirical evidence in Section 3.2.
} 
as compared with their onshore counterparts (Helm, 1997: 414). ${ }^{7}$ One of the most colorful groups of people to use offshore accounts for legitimate business reasons are professional poker players, who must transact regularly in many world currencies (see O'Reilly, 2007). Accordingly, not all taxpayers who appear in data on offshore holdings owe tax. Hence, we allow for two types of taxpayer: an Honest type who are fully compliant and use an offshore account legitimately, and an Evader type who invest offshore without declaring the source capital for domestic taxation. ${ }^{8}$

In order to appraise the impact of IOVDS we first model the strategic interaction between a taxpayer and the tax authority in the absence of a Scheme. ${ }^{9}$ We then introduce an IOVDS into the model and compare the results found in the presence and absence of a Scheme. A taxpayer - whose type is unobserved by the tax authority - can decide to invest offshore a fixed amount $\omega>0$. If the taxpayer invests, the offshore investment is then observed by the tax authority with a positive probability. If the investment is observed the tax authority audits the taxpayer with a chosen probability in the absence of a Scheme. An equilibrium of this game is inefficient to the extent that some Honest taxpayers are audited, imposing a cost upon them, and wasting the resources of the tax authority. In the presence of a Scheme the tax authority chooses a (potentially incentivized) fine rate that will apply to liabilities disclosed within the Scheme. The taxpayer decides whether or not to make a disclosure under the Scheme. If the taxpayer does not make a disclosure the tax authority will audit with a chosen probability. If the taxpayer does make a disclosure they can either disclose as an Evader and pay a fine at the incentivized rate, or disclose as the Honest type. The tax authority audits those taxpayers disclosing as Honest with a chosen probability (for an Evader might falsely disclose to be Honest).

Following analyses such as Graetz et al. (1986), but different from much of the optimal auditing literature, we assume that the tax authority makes its audit decision last, such that it cannot pre-commit to an audit rule. The only ability to pre-commit we assume on the part of the tax authority is that, having publicly announced the fine rate that it will apply to accepted disclosures within the Scheme, it does not subsequently renege on this

\footnotetext{
${ }^{7}$ Relative to their onshore counterparts in the US, Helm argues that offshore funds have greater flexibility and less procedural delays in changing the nature, structure, or operation of their products, and they face fewer investment restrictions, short-term trading limitations, capital structure requirements, and governance provisions. For evidence on the impact of these differences on the behaviour of onshore and offshore financial institutions see Kim and Wei (2002).

${ }^{8}$ Earlier analyses that allow for the possible existence of honest taxpayers include Hokamp and Pickhardt (2010), Davis et al. (2003) Erard and Feinstein (1994) and Graetz et al. (1986).

${ }^{9}$ In this paper we focus solely on efficiency. There is, however, an equity concern when offering incentives to Evaders. Moreover, only a subset of Evaders (i.e., those that evade through an offshore investment) benefit. There are also moral and legal concerns where tax authorities have purchased information on offshore accounts that was obtained illegally (see, e.g., Pfisterer, 2013). Such equity concerns might impinge on the efficiency arguments for IOVDS were they to adversely affect compliance behavior among evaders not offered such Schemes, or more widely in the population at large (although we are unaware of any formal or anecdotal evidence to this effect). See, e.g., Bordignon (1993) and Rablen (2010) for studies of the role of equity in influencing tax evasion.
} 
announcement. The many IOVDS implemented to date demonstrate empirically that tax authorities are able to commit in this way. Allowing the tax authority to pre-commit to an audit rule can never weaken, and will typically strengthen, its hand. It is therefore of interest to ask whether IOVDS can be gainful for a tax authority even when it cannot commit to an audit rule. ${ }^{10}$

We find that an optimal Scheme can result in a Pareto improvement over a traditional audit-based enforcement approach. Taxpayers of both types are never made worse-off by the introduction of a Scheme and the tax authority can raise a higher net revenue. In particular, the introduction of an IOVDS benefits Honest taxpayers by permitting them opportunities to signal their type, thereby reducing their probability of suffering a burdensome audit. Evaders find their welfare reduced by the enhanced ability of the tax authority to infer their type in the Scheme, but benefit from the incentives provided within the Scheme and from the increased potential to "hide" among Honest investors (who become more inclined to invest offshore in the presence of a Scheme). IOVDS can also increase the net revenue of the tax authority as, when an Evader discloses truthfully within the Scheme, revenue is generated without the cost of an audit being incurred. We give conditions under which it is optimal for the tax authority to offer overt incentives for honesty within the Scheme. This requires, in particular, that it is sufficiently costly for an Evader to meet the evidential requirements of the Scheme if making a false disclosure. In this case the tax authority optimally "captures" the taxpayer's cost of making a false disclosure by setting the incentivized fine rate just low enough to make Evaders strictly prefer to disclose truthfully. When the cost of making a false disclosure is too low and the offshore evasion gamble is sufficiently attractive the optimal Scheme does not offer incentives. Such unincentivized Schemes can still Pareto improve upon the outcome with no Scheme, however.

The introduction of IOVDS never decreases the total amount of offshore investment (and typically increases it). In particular, Honest taxpayers will always invest offshore in the presence of a Scheme offering incentives for truthful disclosure, whereas they might otherwise have been put-off investing offshore in the absence of a Scheme by the possibility of being caught-up in tax authority audit activity. We show that under some conditions illegal offshore evasion will also increase, this being more likely when the investment amount is large, and when the Scheme is incentivized.

Our analysis relates to a number of literatures. First, we connect to a literature on the use by tax authorities of pre-audit settlements (e.g., Chu, 1990; Glen Ueng and Yang, 2001) in which taxpayers can pay a given amount of tax in return for immunity from audit. These procedures are shown to yield a Pareto improvement relative random auditing as (i) the tax authority captures the positive risk premium of a risk averse taxpayer and (ii) the tax authority conducts fewer audits. It is notable that, in the model we consider, such settlement procedures do not induce a Pareto improvement as neither of these effects holds. First, we

\footnotetext{
${ }^{10}$ For a detailed discussion of pre-commitment possibilities, see, e.g., Reinganum and Wilde (1986) and Melumad and Mookherjee (1989).
} 
consider risk neutral taxpayers, so the tax authority is not able to extract a positive risk premium. Second, we assume the tax authority audits optimally with and without a Scheme, which rules out random auditing. In particular, in our model the tax authority does not gain from a reduction in the number of audits it performs per se, as it only ever audits when it is gainful in expectation to do so. It is therefore notable that we find that IOVDS can be Pareto improving even under these stringent assumptions. Were we to allow for risk averse taxpayers the introduction of a Scheme would likewise allow the tax authority to capture the taxpayer's risk premium, so the effects on net revenue we attribute to the introduction of a Scheme should be considered a lower bound on the true effect in this respect.

A further important feature of the settlement literature discussed above is that it fails to take into account the potential for the pre-audit settlement to affect the incentives for taxpayers to evade in the first place. As our model examines both the initial decision by the taxpayer to evade, as well as the taxpayer's subsequent disclosure decision under the IOVDS, it is in this sense more closely associated with the literature investigating tax amnesties, by which we mean schemes run in the absence of new non-audit information, which nevertheless offer taxpayers reduced penalties if they wish to revise (upwards) their past tax returns. Such tax amnesties are analyzed using theoretical (e.g., Andreoni, 1991; Franzoni, 2000; MachoStadler et al., 1993; Malik and Schwab, 1991; Stella, 1991), empirical (e.g., Alm and Beck, 1993) and experimental (Alm et al., 1990) methods. In our model, taxpayers would never disclose under an amnesty, but may make a disclosure under an IOVDS. The reason is that the tax authority learns new information between the taxpayer choosing to invest offshore and the taxpayer being offered to opportunity to disclose under an IOVDS. In this way, voluntary disclosure takes place in the shadow of a credible threat of sanctions for underdisclosure. In contrast, an amnesty provides no new information to the taxpayer, so rational and fully-informed taxpayers will never participate (Andreoni, 1991; Malik and Schwab, 1991). ${ }^{11}$ Whereas the literature has cast doubt on the desirability to tax authorities of amnesties, the analysis of IOVDS arrives at more positive conclusions.

Our work also connects to the literature on law enforcement with self-reporting (e.g., Kaplow and Shavell, 1994; Feess and Heesen, 2002; Feess and Walzl, 2005). In this literature truthful self-reporting is induced by allowing those who report to pay a sanction equal to the certainty equivalent of the expected sanctions they would otherwise face by not self-reporting. Results of this type, however, rely on the idea that the tax authority can commit to auditing taxpayers that it knows will be honest in equilibrium, which we do not assume here. A second related literature is that on optimal auditing in the presence of signals (e.g., Scotchmer, 1987; Macho-Stadler and Pérez-Castrillo, 2002; Bigio and Zilberman, 2011). Under a Scheme the act of making a disclosure, and its nature, are both signals the tax authority observes before deciding whether or not to audit. Last, as the ability of tax authorities to extract

\footnotetext{
${ }^{11}$ To overcome this difficulty, the amnesty literature posits that either (i) taxpayers learn new information regarding their own characteristics after the time of the initial reporting decision (e.g., Andreoni, 1991; Malik and Schwab, 1991) or (ii) the tax authority cannot control all of its enforcement parameters (Franzoni, 2000). Such assumptions are not necessary in the current context.
} 
revenue from whistleblower data influences the degree to which they should incentivize such behavior, our findings inform the literature on the optimal incentivization of whistleblowing (Yaniv, 2001) and complement studies that analyze the effects on compliance of the presence of potential whistleblowers (Mealem et al., 2010; Bazart et al., 2014).

The paper proceeds as follows: Section 2 presents the model with and without an IOVDS; Section 3 examines the consequences of the introduction of a Scheme for expected net revenue and for taxpayer welfare; and Section 4 concludes.

\section{Model}

In this section we model IOVDS as a strategic interaction between a taxpayer who can invest offshore and the domestic tax authority. Of course, in reality, IOVDS involve many taxpayers, not just one. Strictly speaking, the equilibria we analyze for the game with a single taxpayer are not equilibria of the game between the tax authority and the whole taxpayer population affected by a Scheme. An equilibrium strategy of the tax authority for the whole game (i.e., the game against all taxpayers affected by a Scheme) can be obtained simply by independently replicating the one-to-one strategy, however.

\subsection{Preliminaries}

A taxpayer receives a lump-sum $w>0$, unobserved by the tax authority. We assume two types of taxpayer: Honest $(H)$ and Evader $(E)$. In the context of an Honest taxpayer the lump-sum might be thought of as the winnings of a professional poker player, and in the context of an Evader, the lump-sum might be thought of as a bequest. The taxpayer should, by law, declare the lump-sum for taxation at the marginal rate $\theta \in(0,1)$. Honest taxpayers pay $\theta w$ in tax on the lump-sum, and then choose to invest an amount $\omega \leq[1-\theta] w$ offshore. Any amount not invested is then consumed. In contrast, Evaders $(E)$ can choose to invest an amount $\omega \leq w$ offshore before tax. They then pay $\theta[w-\omega]$ in tax, and consume any remainder. Both taxpayer types consume the investment amount (plus interest earnings) upon its maturity. ${ }^{12}$

We denote by $p_{H} \in(0,1)$ the probability that the taxpayer is Honest, and by $p_{E}=1-p_{H}$, the probability that the taxpayer is an Evader. The tax authority knows these probabilities, but not the type of any one taxpayer. The taxpayer and tax authority are both assumed to be risk neutral. The taxpayer behaves so as to maximize expected consumption and, for

\footnotetext{
${ }^{12}$ Pritchard and Khan (2005) note a potential third type of taxpayer who pays tax on the lump-sum fully, but then fails to declare the interest on their offshore investment. Our principal reason for emphasizing the evasion of source capital over the evasion of interest income is that cases of the former type are of greater economic significance: the amount of source capital is typically many times the annual interest flow such that only when undeclared interest has accrued over many years does the tax liability from this source become of a comparable magnitude to that on the undeclared capital.
} 
simplicity, we de-emphasize the intertemporal dimension of consumption by assuming a time preference rate of unity. The tax authority behaves so as to maximize revenue (comprising voluntary compliance, tax recovered by audit, and fines) net of enforcement costs.

\subsection{No Scheme}

In order to appraise IOVDS, we now model the "do nothing" benchmark case in which the tax authority does not offer a Scheme (NS). The game in the absence of a Scheme is set out in Figure 1. At the outset, nature determines the taxpayer's type (but this action is unobserved by the tax authority). Next the taxpayer makes an offshore investment choice; a taxpayer of type $j \in\{E, H\}$ can choose to invest an amount $\omega>0$ offshore with probability $\phi_{j} \in[0,1]$. If the taxpayer invests, the tax authority subsequently observes the investment amount $\omega$ with probability $p_{I} \in(0,1)$, where this probability reflects the possibility that a whistleblower comes forward, or that a new tax-sharing agreement is signed. We assume here for simplicity that the tax authority acquires information at zero cost, as was indeed the case in many of the Schemes discussed in the Introduction. ${ }^{13}$ Clearly, however, any amount paid to acquire information must be set against any gains accruing from the Scheme. If nonaudit information is not received by the tax authority the offshore tax evasion of an Evader goes undetected with probability one, and the game ends. ${ }^{14}$ If information is observed the tax authority can spend an amount $c_{A}>0$ to perform a verification audit that reveals the taxpayer's type with certainty. The tax authority decides to audit an observed investment with probability $\alpha \in[0,1]$.

If a tax liability is detected by an audit, the tax authority levies fines on the undeclared tax - as in Yitzhaki (1974) - at a rate belonging to the non-empty interval $[\underline{f}, \bar{f}] \in \mathbb{R}_{>0}$. We interpret the bounds on the fine rate as being specified in national legislation. In the UK, for instance, civil fraud legislation sets $\underline{f}=0.1$ and $\bar{f}=1$, where the actual fine rate that is applied is conditional upon the "behavioral" nature of the observed non-compliance: the lower bound, $f$, applies if the non-compliance is judged to be through "careless error", whereas the upper bound applies to "deliberate and concealed" inaccuracies (see, e.g., HMRC, 2012). Prior to performing an audit neither the tax authority nor the taxpayer know the fine rate that will ultimately be applied, but both know the expected fine, which we denote by $f \in(\underline{f}, \bar{f})$. The expected yield (recovered tax plus penalties) the tax authority receives if it audits an Evader is therefore given by

\footnotetext{
${ }^{13}$ Even when payments were made, the amounts involved - where known - appear relatively modest in relation to the revenue generated. The British tax authority is reported to have paid a former Liechtenstein bank employee a fee of just $£ 100,000$ for information regarding more than $£ 100$ million of offshore funds (Oates, 2008). Bradley Birkenfeld, a UBS employee who acted as an IRS informer received a payment of USD 104 million, but in the context of some USD 3.4 billion that was eventually raised by the resulting Scheme (GAO, 2013).

${ }^{14}$ In reality, a small proportion of Evaders might be audited outside of the Scheme if some other aspect of their tax affairs triggers an audit, or if they are selected for a random audit. We abstract from these complications here.
} 


$$
Q(f, \omega)=\theta[1+f] \omega .
$$

Being audited is burdensome to taxpayers, even if no undeclared liability is discovered, for audits can cause psychological distress, disruption, and reputational costs. These additional burdens associated with being audited we denote by $b>0$.

The expected consumption of the taxpayer is therefore

$$
\begin{aligned}
& C_{H}^{N S}(\alpha, \omega)=[1-\theta] w+r \omega-p_{I} \alpha b ; \\
& C_{E}^{N S}(\alpha, \omega)=[1-\theta] w+[\theta+r] \omega-p_{I} \alpha[b+Q(f, \omega)] ;
\end{aligned}
$$

where $r>0$ is the rate of return (net of any management fees) earned on the offshore investment. Note in the second term of (3) that Evaders, by investing pre-tax, implicitly make a return of $\theta+r$ on their offshore investment, for they evade tax that would otherwise have applied at the rate $\theta$. The third term in each of (2) and (3) is the expected loss of consumption arising from tax authority enforcement; both $E$ - and $H$-types suffer the burden $b$ when audited, but only Evaders are additionally liable for $Q(f, \omega)$.

We look for Bayesian-perfect equilibria. As these are numerous we focus on those with empirically relevant characteristics. In particular we require the following hold:

A0. $\quad \alpha>0$

A1. $\phi_{E}>0 ; \phi_{H}>0$.

Assumption A0 may be interpreted as requiring the investment amount $\omega$ to be sufficiently large that, given the other the parameters of the model, it is gainful in expectation for the tax authority to audit. Of course, when offshore information is acquired, some of the observed holdings are too low to be worthwhile pursuing. But as these cases can be almost costlessly screened by the tax authority it seems appropriate to focus on the larger investment amounts. ${ }^{15}$ As the model is both uninteresting and unrealistic unless both taxpayer types are willing to invest offshore with a positive probability, assumption A1 rules out equilibria without this feature. It transpires that a necessary condition to achieve these two assumptions is that, at the prior probabilities $\left\{p_{E}, p_{H}\right\}$, the tax authority finds it gainful to audit:

$$
p_{E} Q(f, \omega)-c_{A} \geq 0 .
$$

We take (4) to hold in what follows.

\footnotetext{
${ }^{15}$ The amounts invested offshore are often considerable. According to Watt et al. (2012), the list of HSBC Jersey account holders obtained by HMRC in 2012 identifies 4,388 people holding £699 million in offshore current accounts, which implies an average holding of $£ 159,000$. The median account balance of more than 10,000 closed cases from the 2009 OVDP in the United States is reported as USD 570,000 in GAO (2013).
} 
If a taxpayer of type $j$ invests offshore they obtain an expected payoff $C_{j}(\alpha, \omega)$, and if they choose not to invest they obtain the certain payoff $C_{j}(0,0)$. Hence, in equilibrium,

$$
\phi_{j} \begin{cases}=0 & \Leftrightarrow C_{j}(\alpha, \omega) \leq C_{j}(0,0) \\ \in(0,1) & \Leftrightarrow C_{j}(\alpha, \omega)=C_{j}(0,0) \\ =1 & \Leftrightarrow C_{j}(\alpha, \omega) \geq C_{j}(0,0)\end{cases}
$$

The tax authority's expected payoff from performing an audit is given by

$$
R^{N S}=p_{E} \phi_{E} Q(f, \omega)-\left[p_{E} \phi_{E}+p_{H} \phi_{H}\right] c_{A}
$$

Hence, in equilibrium,

$$
\alpha \begin{cases}=0 & \Leftrightarrow R^{N S} \leq 0 \\ \in(0,1) & \Leftrightarrow R^{N S}=0 \\ =1 & \Leftrightarrow R^{N S} \geq 0\end{cases}
$$

Proposition 1 In an equilibrium under No Scheme satisfying AO and A1:

(a) If

$$
r+\theta-\theta p_{I}[1+f] \leq 0 ; \quad \omega \geq \frac{b}{r[1+f]}
$$

then

(i) A taxpayer of type $j \in\{E, H\}$ invests $\omega$ with probability

$$
\phi_{E}^{N S}=\left\{\begin{array} { l l } 
{ \frac { p _ { H } c _ { A } } { p _ { E } [ Q ( f , \omega ) - c _ { A } ] } \phi _ { H } ^ { N S } } & { \text { if } \omega = \frac { b } { r [ 1 + f ] } ; } \\
{ \frac { p _ { H } c _ { A } } { p _ { E } [ Q ( f , \omega ) - c _ { A } ] } } & { \text { if } \omega > \frac { b } { r [ 1 + f ] } ; }
\end{array} \quad \phi _ { H } ^ { N S } \left\{\begin{array}{ll}
\in(0,1] & \text { if } \omega=\frac{b}{r[1+f]} ; \\
=1 & \text { if } \omega>\frac{b}{r[1+f]} .
\end{array}\right.\right.
$$

(ii) The tax authority audits an observed investment with probability

$$
\alpha=\frac{[r+\theta] \omega}{[b+Q(f, \omega)] p_{I}} .
$$

(b) If

$$
\omega \geq \max \left\{\frac{b p_{I}}{r}, \frac{b p_{I}}{r+\theta-\theta p_{I}[1+f]}\right\} ;
$$

then

(i) Both taxpayer types invest $\omega$ for sure $\left(\phi_{E}^{N S}=\phi_{H}^{N S}=1\right)$.

(ii) The tax authority audits an observed investment with probability $\alpha=1$.

As verifying the statements in parts (a) and (b) of Proposition 1 meet the equilibrium conditions in (5) and (6) is straightforward, we omit the proof. According the proposition, the nature of the equilibrium is importantly affected by the sign of the expression $r+\theta-$ $\theta p_{I}[1+f]$, which can be interpreting as indexing the attractiveness of offshore evasion to an Evader. Specifically, $r+\theta$ is the marginal benefit of offshore evasion, which is offset against 
its marginal cost (arising from tax authority enforcement activity), $\theta p_{I}[1+f]$. Part (a) of the Proposition gives the equilibrium arising when offshore evasion is sufficiently unattractive $\left(r+\theta-\theta p_{I}[1+f] \leq 0\right)$, and part (b) when it is sufficiently attractive $\left(r+\theta-\theta p_{I}[1+f] \geq\right.$ 0 ). In the equilibrium of part (a) the tax authority is indifferent between auditing or not, Evaders are indifferent between investing or not, and Honest taxpayers are either indifferent between investing or not, or have a strict preference for investing. The conditions required to support an equilibrium of this type are given at the head of part (a). The first condition is required to ensure $\alpha \leq 1$ when $\omega \geq b / r[1+f]$. Taking the limit as $\omega \rightarrow \infty$ we obtain $\alpha \leq[r+\theta] / \theta p_{I}[1+f]$, so $\alpha \leq 1$ requires $r+\theta-\theta p_{I}[1+f] \leq 0$. The second condition guarantees that $\omega \geq b / r[1+f]$ (for if $\omega<b / r[1+f]$ it is never part of an equilibrium strategy for an Evader to invest offshore, violating A1). Note that the condition in (4) guarantees $\phi_{E}^{N S} \leq 1$.

The only equilibrium possibility meeting A0 and A1 when $r+\theta-\theta p_{I}[1+f] \geq 0$ is given in part (b) of the Proposition. The conditions needed to support an equilibrium of this type are that (i) the tax authority has a preference to audit, as guaranteed by (4), (ii) an Honest taxpayer has a preference to invest $\left(\omega r \geq p_{I} b\right)$, and (iii) an Evader has a preference to invest $\left([r+\theta] \omega \geq p_{I}[b+Q(f, \omega)]\right)$. The requirement that offshore evasion is sufficiently attractive $\left(r+\theta-\theta p_{I}[1+f] \geq 0\right)$ is a necessary condition for this last inequality to hold.

Note that in equilibrium the tax authority audits an Honest taxpayer with a positive probability. When this occurs, it results in a loss to the taxpayer of $b$, and a loss to the tax authority of $c_{A}$. We shall now examine whether this welfare loss can be mitigated, or avoided altogether, in the presence of a Scheme.

\subsection{The Scheme}

We now suppose the tax authority offers a Scheme in the event that information is observed. The game is set out in Figure 2. The initial hidden action by nature and the subsequent investment decision are modelled in the same way as in the absence of a Scheme. If information is observed, however, the tax authority must now choose the terms of the Scheme it will announce to the taxpayer. In particular, the tax authority chooses an incentivized fine rate $\hat{f} \in[f, f]$. A taxpayer of type $j$ then chooses to participate in the Scheme with probability $\gamma_{j} \in[0,1]$. If the taxpayer does participate s/he discloses a type $d \in\{E, H\}$ and must also provide supporting evidence. To provide genuine documentation would presumably be relatively straightforward for the taxpayer, but to produce false documents would presumably be significantly more costly. Accordingly, we normalize the costs of providing true documentation to zero, and the cost of producing false documents (by, for instance, paying a criminal agent) we write as $s>0$. The probability that a taxpayer of type $j$ chooses to disclose $d=H$ is denoted as $\lambda_{j} \in[0,1]$. A taxpayer disclosing $d=E$ accompanies their disclosure with a payment to the tax authority of $Q(\hat{f}, \omega)$, but a taxpayer disclosing themselves as Honest makes no accompanying payment. The tax authority then audits the disclosure $d=H$ with probability $\alpha_{\mathrm{IN}} \in[0,1]$ and never audits the disclosure $d=E$. Audited taxpayers have 
their type revealed with certainty, and an Evader revealed to have disclosed falsely is subject to the maximum allowable fine rate $\bar{f}$ on their full tax liability. When a taxpayer does not participate in the Scheme the tax authority can choose to audit them with probability $\alpha_{\text {OUT }} \in[0,1]$. Again, such an audit reveals the taxpayer's type with certainty. The taxpayer is then fined at the expected rate $f$, just as they would be in the absence of a Scheme. ${ }^{16}$

To restrict the set of equilibria in a manner similar to that of the previous section, we retain A1 and generalize A0 with

A2. $\alpha_{\mathrm{IN}}+\alpha_{\mathrm{OUT}}>0$

which requires the tax authority to be willing to audit either inside or outside the Scheme (or both). We make a further assumption

A3. $\gamma_{E}+\gamma_{H}>0$

that rules out uninteresting cases in which both taxpayer types choose to Not Enter the Scheme with certainty (the equilibrium payoffs are identical to those in the model without a Scheme, rendering the introduction of a Scheme Pareto neutral).

Consider the subgame that arises when the taxpayer participates in the Scheme. The expected net revenue from auditing in the Scheme is given by

$$
R^{S}=p_{E} \phi_{E} \gamma_{E} \lambda_{E} Q(\bar{f}, \omega)-\left[p_{E} \phi_{E} \gamma_{E} \lambda_{E}+p_{H} \phi_{H} \gamma_{H} \lambda_{H}\right] c_{A}
$$

hence

$$
\alpha_{\mathrm{IN}} \begin{cases}=0 & \Leftrightarrow R^{S} \leq 0 \\ \in(0,1) & \Leftrightarrow R^{S}=0 \\ =1 & \Leftrightarrow R^{S} \geq 0\end{cases}
$$

Note that as either $\phi_{E} \rightarrow 0$ or $\lambda_{E} \rightarrow 0$ it must be that $\alpha_{\mathrm{IN}}=0$. An Evader is indifferent between disclosing $d=E$ or $d=H$ if

$$
s+\alpha_{\mathrm{IN}}[b+Q(\bar{f}, \omega)]=Q(\hat{f}, \omega),
$$

where the left-side is the expected payoff from falsely disclosing $d=H$, and the right-side is the certain payoff from disclosing truthfully. Hence

$$
\lambda_{E} \begin{cases}=0 & \Leftrightarrow \alpha_{\mathrm{IN}} \geq \frac{Q(\hat{f}, \omega)-s}{b+Q(\bar{f}, \omega)} ; \\ \in(0,1) & \Leftrightarrow \alpha_{\mathrm{IN}}=\frac{Q(\hat{f}, \omega)-s}{b+Q(\bar{f}, \omega)} ; \\ =1 & \Leftrightarrow \alpha_{\mathrm{IN}} \leq \frac{Q(\hat{f}, \omega)-s}{b+Q(\bar{f}, \omega)} .\end{cases}
$$

\footnotetext{
${ }^{16}$ In this sense we make the conservative assumption that the tax authority cannot use the failure of a taxpayer to participate in the Scheme as grounds for imposing a higher fine rate. We return to this point in the later discussion.
} 
From (10) we learn that for $\lambda_{E} \in(0,1]$ to be part of an equilibrium strategy it must be that $s \leq Q(\hat{f}, \omega)$, a necessary condition for which is $s \leq Q(f, \omega)$. Second, combining (8) and (10) we see that when $\lambda_{E}=0$ we have $\alpha_{\mathrm{IN}}=0$, so the condition for $\lambda_{E}=0$ in (10) reduces to $s \geq Q(\hat{f}, \omega)$. A necessary condition for $\lambda_{E}=0$ to be part of an equilibrium strategy is therefore $s \geq Q(f, \omega)$. So as not to rule out any of the three possibilities for $\lambda_{E}$ in (10) a-priori, we assume

$$
s \in[Q(\underline{f}, \omega), Q(f, \omega)] .
$$

An Honest taxpayer expects to lose $b \alpha_{\mathrm{IN}}$ as a result of tax authority enforcement if they disclose truthfully, and to lose $s+Q(\hat{f}, \omega)$ if they were to disclose (falsely) as an Evader. Hence

$$
\lambda_{H} \begin{cases}=0 & \Leftrightarrow \alpha_{\mathrm{IN}} \geq \frac{s+Q(\hat{f}, \omega)}{b} ; \\ \in(0,1) & \Leftrightarrow \alpha_{\mathrm{IN}}=\frac{s+Q(\hat{f}, \omega)}{b} ; \\ =1 & \Leftrightarrow \alpha_{\mathrm{IN}} \leq \frac{s+Q(\hat{f}, \omega)}{b} .\end{cases}
$$

We now show that, in equilibrium, an Honest taxpayer will always disclose truthfully $\left(\lambda_{H}=\right.$ 1). From (12), this is equivalent to demonstrating that $\alpha_{\mathrm{IN}} \leq[s+Q(\hat{f}, \omega)] / b$. If $\lambda_{E}=0$ we have $\alpha_{\mathrm{IN}}=0$ so necessarily $\alpha_{\mathrm{IN}} \leq[s+Q(\hat{f}, \omega)] / b$. Alternatively, if $\lambda_{E} \in(0,1]$ then, from (10), we again have

$$
\alpha_{\mathrm{IN}} \leq \frac{Q(\hat{f}, \omega)-s}{b+Q(\bar{f}, \omega)}<\frac{Q(\hat{f}, \omega)-s}{b}<\frac{Q(\hat{f}, \omega)+s}{b} .
$$

\subsubsection{Entry Decision}

An Honest taxpayer expects to lose $b \alpha_{\text {OUT }}$ as a result of tax authority enforcement if they do not Enter the Scheme. Given $\lambda_{H}=1$, they expect to lose $b \alpha_{\mathrm{IN}}$ if they do Enter. Hence

$$
\gamma_{H} \begin{cases}=0 & \Leftrightarrow \alpha_{\text {OUT }} \leq \alpha_{\mathrm{IN}} ; \\ \in(0,1) & \Leftrightarrow \alpha_{\text {OUT }}=\alpha_{\mathrm{IN}} ; \\ =1 & \Leftrightarrow \alpha_{\text {OUT }} \geq \alpha_{\mathrm{IN}} .\end{cases}
$$

An Evader expects to lose $\alpha_{\text {OUT }}[b+Q(f, \omega)]$ as a result of tax authority enforcement if they do not Enter the Scheme and to lose $\left[1-\lambda_{E}\right] Q(\hat{f}, \omega)+\lambda_{E}\left\{s+\alpha_{\mathrm{IN}}[Q(\bar{f}, \omega)+b]\right\}$ if they do. Hence, for an Evader to be indifferent between Entering and Not Entering the Scheme requires

$$
\alpha_{\mathrm{OUT}}=\frac{\left[1-\lambda_{E}\right] Q(\hat{f}, \omega)+\lambda_{E}\left\{s+\alpha_{\mathrm{IN}}[Q(\bar{f}, \omega)+b]\right\}}{b+Q(f, \omega)} .
$$

We now establish that Evader is never indifferent between Entering and Not Entering. To see this, suppose the contrary, in which case (14) holds. Then, using (10) we have 


$$
\alpha_{\mathrm{OUT}}= \begin{cases}\frac{Q(\hat{f}, \omega)}{b+Q(f, \omega)}<1 & \text { if } \lambda_{E} \in[0,1) \\ \frac{s+\alpha_{\mathrm{IN}}[b+Q(\hat{f}, \omega)]}{b+Q(f, \omega)} \leq \frac{Q(\hat{f}, \omega)}{b+Q(f, \omega)}<1 & \text { if } \lambda_{E}=1\end{cases}
$$

so $\alpha_{\text {OUT }}<1$. Next note that $(14)$ can be rewritten as

$$
\alpha_{\mathrm{OUT}}-\alpha_{\mathrm{IN}}=\frac{\left[1-\lambda_{E}\right] Q(\hat{f}, \omega)+\lambda_{E} s+\alpha_{\mathrm{IN}}\left\{\lambda_{E} Q(\bar{f}, \omega)-Q(f, \omega)-\left[1-\lambda_{E}\right] b\right\}}{b+Q(f, \omega)} .
$$

For $\lambda_{E}=0$ we have $\alpha_{\mathrm{IN}}=0$ so $\alpha_{\text {OUT }}-\alpha_{\mathrm{IN}}=\alpha_{\text {OUT }}>0$. For $\lambda_{E} \in(0,1)$ we have

$$
\begin{aligned}
\alpha_{\text {OUT }}-\alpha_{\mathrm{IN}} & =\frac{Q(\hat{f}, \omega)[b+Q(\bar{f}, \omega)]-[Q(\hat{f}, \omega)-s][b+Q(f, \omega)]}{[b+Q(f, \omega)][b+Q(\bar{f}, \omega)]} \\
& \geq \frac{s}{b+Q(f, \omega)}>0
\end{aligned}
$$

and for $\lambda_{E}=1$ we have

$$
\alpha_{\mathrm{OUT}}-\alpha_{\mathrm{IN}}=\frac{s+\alpha_{\mathrm{IN}}[Q(\bar{f}, \omega)-Q(f, \omega)]}{b+Q(f, \omega)}>0 .
$$

Hence $\alpha_{\text {OUT }}>\alpha_{\text {IN }}$, which, from (13), implies $\gamma_{H}=1$. Given that an Honest taxpayer would always Enter the Scheme, the tax authority knows any taxpayer who chooses to Not Enter is an Evader, so will audit for sure. But then $\alpha_{\mathrm{OUT}}=1$, which contradicts the finding in (15) that $\alpha_{\text {OUT }}<1$.

This result implies that Evaders have a preference for or against Entering the Scheme. If the preference is against entering the only possible equilibrium is when neither taxpayer type Enters the Scheme, a possibility ruled out by assumption A3: As the arguments above illustrate, it can never be an equilibrium action for an Evader to wish to Not Enter the Scheme when an Honest taxpayer will Enter, for then the tax authority will not audit in the Scheme, which will, in turn, induce an Evader to wish to Enter. The only remaining possibility is therefore that an Evader has a preference for Entering the Scheme $\left(\gamma_{E}=1\right)$, so

$$
\alpha_{\mathrm{OUT}}>\frac{\left[1-\lambda_{E}\right] Q(\hat{f}, \omega)+\lambda_{E}\left\{s+\alpha_{\mathrm{IN}}[Q(\bar{f}, \omega)+b]\right\}}{b+Q(f, \omega)}>\alpha_{\mathrm{IN}} .
$$

As $\alpha_{\mathrm{OUT}}>\alpha_{\mathrm{IN}}$ we obtain $\gamma_{H}=1$ from (13).

As both taxpayer types will choose to Enter the Scheme in equilibrium, the action "Not Enter" is observed only if the taxpayer were to "tremble". In this case the tax authority would have to rely on the prior probabilities $\left\{\phi_{E} p_{E}, \phi_{H} p_{H}\right\}$ in making its audit decision. As (16) implies $\alpha_{\text {OUT }}>0$ the tax authority must be at worst indifferent between auditing or 
not. This therefore implies $p_{E} \phi_{E} Q(f, \omega)-\left[p_{E} \phi_{E}+p_{H} \phi_{H}\right] c_{A} \geq 0$, which may be interpreted as a lower bound on the ratio $\phi_{E} / \phi_{H}$ :

$$
\frac{\phi_{E}}{\phi_{H}} \geq \frac{p_{H} c_{A}}{p_{E}\left[Q(f, \omega)-c_{A}\right]}
$$

\subsubsection{Choosing the incentivized tax rate}

We now consider how the tax authority will choose $\hat{f}$. Given that $\gamma_{E}=\gamma_{H}=\lambda_{H}=1$ the tax authority's expected net revenue from the Scheme (taking $\left\{\phi_{E}, \phi_{H}\right\}$ as given) can be written as

$$
R(\hat{f})=p_{E} \phi_{E}\left\{\lambda_{E} \alpha_{\mathrm{IN}}(\bar{f}) Q(\bar{f}, \omega)+\left[1-\lambda_{E}\right] Q(\hat{f}, \omega)\right\}-\left[p_{E} \phi_{E} \lambda_{E}+p_{H} \phi_{H}\right] \alpha_{\mathrm{IN}}(\hat{f}) c_{A},
$$

where the first term is the expected revenue from the Scheme, and the second is the expected cost. Using the observation that the tax authority is indifferent between auditing or not in the Scheme when $\lambda_{E} \in(0,1)$, (18) reduces further to

$$
R(\hat{f})= \begin{cases}p_{E} \phi_{E} Q(\hat{f}, \omega) & \text { if } \lambda_{E}=0 \\ p_{E} \phi_{E}\left[1-\lambda_{E}\right] Q(\hat{f}, \omega) & \text { if } \lambda_{E} \in(0,1) \\ 0 & \text { if } \lambda_{E}=1\end{cases}
$$

We now consider the choice of $\hat{f}$ that maximizes $R(\hat{f})$. First, if $\lambda_{E}=0, R(\hat{f})$ is increasing in $\hat{f}$ as the tax authority takes $\phi_{E}$ as given. It follows that the tax authority will set $\hat{f}$ maximally, subject to the constraint $s \geq Q(\hat{f}, \omega)$ needed for $\lambda_{E}=0$ to be part of an equilibrium strategy. Hence $\hat{f}$ is set such that $s=Q(\hat{f}, \omega)$, i.e., $\hat{f}=[s-\theta \omega] / \theta \omega$.

If $\lambda_{E} \in(0,1)$ then, from (10), it must be that $s \leq Q(\hat{f}, \omega)$. If the tax authority sets $\hat{f}$ such that $s=Q(\hat{f}, \omega)$ then $\alpha_{\mathrm{IN}}=0$ and net revenue in the Scheme is $p_{E} \phi_{E}\left[1-\lambda_{E}\right] s$. If the tax authority sets $\hat{f}$ such that $s>Q(\hat{f}, \omega)$ then $\alpha_{\mathrm{IN}} \in(0,1)$. As this requires the tax authority be indifferent between auditing or not within the Scheme we have, from (7), that

$$
\lambda_{E}=\frac{p_{H}}{p_{E}} \frac{\gamma_{H}}{\gamma_{E}} \frac{\phi_{H}}{\phi_{E}} \frac{c_{A}}{Q(\bar{f}, \omega)-c_{A}} .
$$

As the expression in (20) is independent of $\hat{f}$, net revenue in the Scheme is maximized by setting $\hat{f}$ maximally, i.e., $\hat{f}=f$. If $\lambda_{E}=1$ net revenue is zero as when no revenue is generated through honest disclosure, expected audit yield is exact offset by audit cost in equilibrium. It follows that the tax authority will never set $\hat{f}$ such that $\lambda_{E}=1$ in equilibrium.

Setting $\hat{f}$ to that which maximizes expected revenue, (19) therefore becomes

$$
R= \begin{cases}p_{E} \phi_{E} s & \text { if } \lambda_{E}=0 \\ p_{E} \phi_{E}\left[1-\lambda_{E}\right] \max \{s, Q(f, \omega)\} & \text { if } \lambda_{E} \in(0,1) \\ 0 & \text { if } \lambda_{E}=1\end{cases}
$$


The tax authority therefore sets

$$
\hat{f}= \begin{cases}\frac{s-\theta \omega}{\theta \omega} & \text { if } s \geq\left[1-\lambda_{E}\right] Q(f, \omega) \\ f & \text { otherwise }\end{cases}
$$

According to (22), it is an equilibrium strategy of the tax authority to set $\hat{f}<f$ so long as $s$ is sufficiently high. The intuition is that at $\hat{f}=[s-\theta \omega] / \theta \omega$ the fine the tax authority levies exactly appropriates the taxpayer's cost of making a false disclosure, s. An Evader then has a preference to disclose truthfully. When $s$ is sufficiently high, this strategy is more gainful to the tax authority than levying a higher fine rate $\hat{f}=f$ which, however, induces an Evader to sometimes disclose falsely.

We now use (22) to understand the conditions under which a Scheme is incentivized in equilibrium, i.e., $\hat{f}<f$. First, we establish that when $\lambda_{E}=0$ is part of an equilibrium it must be that the Scheme is incentivized. To see this recall that $\lambda_{E}=0$ implies $\alpha_{\mathrm{IN}}=0$. Suppose, by contradiction, that $\lambda_{E}=\alpha_{\mathrm{IN}}=0$ and $\hat{f}=f$, then the condition for $\lambda_{E}=0$ to pertain in (10) is $Q(\hat{f}, \omega)=Q(f, \omega)<s$, which violates (11). Second, note (by definition) that $Q(\hat{f}, \omega)>\theta \omega$ so the condition $s=Q(\hat{f}, \omega)$ that holds for an incentivized Scheme implies $s>\theta \omega$ (the cost of making a false disclosure must exceed the amount of unpaid tax liability). The reason an incentivized Scheme emerges only for investment amounts that are sufficiently low relative to $s$ is that the benefits of offshore evasion, $(r+\theta) \omega$, scale in $\omega$, yet the cost of making false disclosure, $s$, is assumed to be fixed for any $\omega$. An alternative assumption might be that the criminal agents who produce false documentation charge a fee for this service that increases in the value of the false documents. If, accordingly, the cost of providing false documents is instead assumed to be $s \omega$ then the condition $s>\theta \omega$ instead becomes $s \omega=\theta \omega$, which holds for $s>\theta$. In this case an incentivized Scheme can arise in equilibrium for any $\omega$. Hence, whether an upper bound exists on the $\omega$ consistent with an incentivized Scheme, and, if so, its level, depends on the structure of the cost of making a false disclosure. The conditions under which an incentivized Scheme is part of an equilibrium strategy are most likely to be satisfied when this cost scales in $\omega$, either for inherent reasons or because the evidential requirements of the Scheme are designed to engender this property. In what follows, however, we retain the most conservative assumption (that $s$ is fixed).

\subsubsection{Investment Decision}

We now consider the decision of the taxpayer whether to invest an amount $\omega$ offshore, or not to invest. The taxpayer makes this decision knowing how it will induce the tax authority to subsequently choose $\hat{f}$. First take the case in which $\left\{\phi_{E}, \phi_{H}\right\}$ are chosen such that the tax authority will subsequently choose $\hat{f}=[s-\theta \omega] / \theta \omega<f$ (an incentivized Scheme). We add a superscript " $i$ " to denote this case. An Evader gains an expected payoff $[1-\theta] w+[r+\theta] \omega-p_{I} s$ from investing offshore. Hence $\phi_{E}$ is determined as 


$$
\phi_{E}^{i} \begin{cases}=0 & \Leftrightarrow[r+\theta] \omega<p_{I} s \\ \in(0,1) & \Leftrightarrow[r+\theta] \omega=p_{I} s \\ =1 & \Leftrightarrow[r+\theta] \omega>p_{I} s\end{cases}
$$

An Honest taxpayer faces no cost of tax authority enforcement if they invest (as $\left.\alpha_{\mathrm{IN}}=0\right)$, so has a strict preference for investing $\left(\phi_{H}^{i}=1\right)$.

Alternatively, $\left\{\phi_{E}, \phi_{H}\right\}$ may be chosen in equilibrium such that the tax authority will subsequently choose $\hat{f}=f$ (an unincentivized Scheme). We add a superscript " $u$ " to denote this case. An Evader who invests gains an investment return $[r+\theta] \omega$ but expects to lose $\theta p_{I}[1+f] \omega$ as a result of tax authority enforcement. Hence $\phi_{E}$ is determined as

$$
\phi_{E}^{u} \begin{cases}=0 & \Leftrightarrow r+\theta-\theta p_{I}[1+f] \leq 0 \\ \in(0,1) & \Leftrightarrow r+\theta-\theta p_{I}[1+f]=0 \\ =1 & \Leftrightarrow r+\theta-\theta p_{I}[1+f] \geq 0\end{cases}
$$

An Honest taxpayer who invests gains an investment return $r \omega$ but expects to lose $p_{I} \alpha_{\mathrm{IN}}^{u} b$ as a result of tax authority enforcement, so in equilibrium

$$
\phi_{H}^{u} \begin{cases}=0 & \Leftrightarrow r \omega-p_{I} \alpha_{\mathrm{IN}}^{u} b \leq 0 \\ \in(0,1) & \Leftrightarrow r \omega-p_{I} \alpha_{\mathrm{IN}}^{u} b=0 \\ =1 & \Leftrightarrow r \omega-p_{I} \alpha_{\mathrm{IN}}^{u} b \geq 0\end{cases}
$$

\subsubsection{Equilibrium}

We now use the derivations above to characterize the equilibria of the model in the presence of a Scheme. We begin with cases featuring an unincentivized Scheme.

Proposition 2 In an equilibrium satisfying $\lambda_{E}=(0,1)$ and $A 1-A 3$ with

$$
\theta+r-p_{I} \theta[1+f] \geq 0 ; \quad s<\frac{p_{E} Q(\bar{f}, \omega)-c_{A}}{p_{E}\left[Q(\bar{f}, \omega)-c_{A}\right]} Q(f, \omega)
$$

(i) An Evader will invest with probability

$$
\phi_{E}^{u} \begin{cases}\in\left[\frac{p_{H}}{p_{E}} \max \left\{\frac{c_{A}}{Q(f, \omega)-c_{A}}, \frac{c_{A}}{Q(\bar{f}, \omega)-c_{A}} \frac{Q(f, \omega)}{Q(f, \omega)-s}\right\} \phi_{H}^{u}, 1\right] & \text { if } r+\theta-\theta p_{I}[1+f]=0 ; \\ =1 & \text { if } r+\theta-\theta p_{I}[1+f]>0 ;\end{cases}
$$

and an Honest taxpayer will invest with probability

$$
\phi_{H}^{u} \begin{cases}\in(0,1] & \text { if } r \omega-\frac{b p_{I}[Q(f, \omega)-s]}{b+Q(\bar{f}, \omega)}=0 \\ =1 & \text { if } r \omega-\frac{b p_{I}[Q(f, \omega)-s]}{b+Q(\bar{f}, \omega)}>0 .\end{cases}
$$


(ii) If it observes information, the tax authority sets $\hat{f}=f$.

(iii) If the tax authority observes their investment, both taxpayer types will Enter the Scheme $\left(\gamma_{E}^{u}=\gamma_{H}^{u}=1\right)$

(iv) Within the Scheme, an Honest taxpayer always discloses truthfully $\left(\lambda_{H}^{u}=1\right)$

(v) The disclosure $d=H$ is audited with probability

$$
\alpha_{I N}^{u}=\frac{Q(f, \omega)-s}{b+Q(\bar{f}, \omega)}
$$

and a taxpayer who chooses (out of equilibrium) to Not Enter the Scheme is audited with probability

$$
\alpha_{O U T}^{u} \in\left(\frac{Q(\hat{f}, \omega)}{b+Q(f, \omega)}, 1\right] .
$$

The first condition at the head of the Proposition clarifies that an unincentivized Scheme arises when offshore evasion is sufficiently attractive. The intuition for this is that, to sustain an unincentivized Scheme, an Evader must be willing to invest offshore with a sufficiently high probability that the tax authority is willing to audit within the Scheme. Once enforcement is tightened to the point that $\theta+r-p_{I} \theta[1+f]<0$ it follows from part (i) of the Proposition that $\phi_{E}^{u}=0$, which violates assumption A1. The bounds provided on $\phi_{E}^{u}$ are necessary and sufficient to ensure (i) that the condition for $\lambda_{E} \in(0,1)$ to be part of an equilibrium strategy in (22) holds; and (ii) that the condition for the ratio $\phi_{E}^{u} / \phi_{H}^{u}$ in (17) holds also. The second condition at the head of the Proposition gives an upper bound for $s$ that ensures that the bounds on $\phi_{E}^{u}$ form a non-empty interval. Intuitively, if $s$ is "too high", it becomes optimal for the tax authority to instead give incentives for truthful disclosure.

When $s$ is sufficiently high, therefore, the equilibrium instead features an incentivized Scheme:

Proposition 3 In an equilibrium satisfying $\lambda_{E}=0$ and A1-A3 with

$$
\omega \geq \frac{p_{I} s}{r+\theta} ; \quad s \geq \frac{p_{E} Q(\bar{f}, \omega)-c_{A}}{p_{E}\left[Q(\bar{f}, \omega)-c_{A}\right]} Q(f, \omega)
$$

(i) An Evader will invest with probability

$$
\phi_{E}^{i} \begin{cases}\in\left[\frac{p_{H} c_{A}}{p_{E}\left[Q(f, \omega)-c_{A}\right]}, 1\right] & \text { if }[r+\theta] \omega=p_{I} s \\ =1 & \text { if }[r+\theta] \omega>p_{I} s\end{cases}
$$

and an Honest taxpayer will invest with probability $\phi_{H}^{i}=1$. 
(ii) If it observes information, the tax authority sets $\hat{f}=\frac{s-\theta \omega}{\theta \omega}<f$.

(iii) If the tax authority observes their investment, both taxpayer types will Enter the Scheme $\left(\gamma_{E}^{i}=\gamma_{H}^{i}=1\right)$.

(iv) Within the Scheme, both taxpayer types disclose truthfully $\left(\lambda_{E}^{i}=0, \lambda_{H}^{i}=1\right)$.

(v) The disclosure $d=H$ is not audited $\left(\alpha_{I N}^{i}=0\right)$ and a taxpayer who chooses (out of equilibrium) to Not Enter the Scheme is audited with probability

$$
\alpha_{\text {OUT }}^{i} \in\left(\frac{s}{b+Q(\bar{f}, \omega)}, 1\right]
$$

According to the Proposition, the investment amount must satisfy $\omega \geq p_{I} s /[r+\theta]$ in order for an Evader to be willing to invest offshore with a positive probability. This condition implies that $s \leq Q(f, \omega)$, as required by (11), when $\theta+r-p_{I} \theta[1+f] \leq 0$. When $\theta+$ $r-p_{I} \theta[1+f]>0$, however, the condition $s \leq Q(f, \omega)$ implies $\omega>p_{I} s /[r+\theta]$, thereby ruling out the case $\omega=p_{I} s /[r+\theta]$ in this instance. The second condition at the head of the Proposition ensures that $s$ is sufficiently high that the condition in $(22)$ for $\lambda_{E}=0$ to be part of an equilibrium strategy holds.

The model therefore predicts conditions under which it is part of an equilibrium strategy for a tax authority to offer an incentivized fine rate. This finding is of interest as it fits the empirical evidence pointing to the existence of such incentivized Schemes. Moreover, it demonstrates that the desirability of levying fines at the maximal rate need not hold in this setting. The model predicts that incentivization of the Scheme is not always a feature of equilibrium, yet incentivized Schemes predominate empirically. This may be due to the observation that, the conditions for an incentivized Scheme do not restrict the sign of $\theta+r-p_{I} \theta[1+f]$, whereas unincentivized Scheme can arise only when this quantity is positive. A further factor that might help account for this observation is the salience to taxpayers of a lower fine rate; this feature is emphasized in tax authority's own marketing of such Schemes, and also in wider media coverage. In this sense, it is consistent with the nascent literature on tax salience (e.g., Chetty et al., 2009; Krishna and Slemrod, 2003) that the up-front offer of an incentivized fine rate may be of greater salience to taxpayers than are the more complex deductive inferences that taxpayers are held to make in the model. Also, the conditions under which an incentivized equilibrium occurs are relaxed if it is alternatively assumed that the tax authority can apply higher fine rates to taxpayers who Stay Out of the Scheme (we assume, conservatively, that the same expected fine rate $f$ applies to those who choose not to enter the Scheme as applies in the absence of a Scheme).

\section{Analysis}

We now analyze the consequences of introducing a Scheme for the net expected revenue of the tax authority and for the welfare of the two possible taxpayer types. In particular, we 
are interested in the question of whether the introduction of a Scheme can lead to a Pareto improvement.

\subsection{Welfare Implications}

From Propositions 1-3 the expected payoff to an Evader under No Scheme, under an incentivized Scheme, and under an unincentivized Scheme are given as:

$$
\begin{aligned}
C_{E}^{N S}=[1-\theta] w+ \begin{cases}0 & \text { if } \theta+r-p_{I} \theta[1+f] \leq 0 \\
{[\theta+r] \omega-p_{I}[b+Q(f, \omega)]} & \text { if } \theta+r-p_{I} \theta[1+f] \geq 0 .\end{cases} \\
C_{E}^{i}=[1-\theta] w+[r+\theta] \omega-p_{I} s \\
C_{E}^{u}=[1-\theta] w+ \begin{cases}0 & \text { if } \theta+r-p_{I} \theta[1+f]=0 ; \\
{[r+\theta] \omega-p_{I} \alpha_{\mathrm{IN}}^{u}[b+Q(f, \omega)]} & \text { if } \theta+r-p_{I} \theta[1+f]>0 .\end{cases}
\end{aligned}
$$

The equivalent payoffs for an Honest taxpayer are given by

$$
\begin{aligned}
C_{H}^{N S} & =[1-\theta] w+r \omega- \begin{cases}p_{I} \alpha b & \text { if } \theta+r-p_{I} \theta[1+f] \leq 0 \\
p_{I} b & \text { if } \theta+r-p_{I} \theta[1+f]>0\end{cases} \\
C_{H}^{i} & =[1-\theta] w+r \omega ;
\end{aligned}
$$

The expected net revenue of the tax authority comprises up to three parts. It necessarily includes (i) the revenue raised through the voluntary compliance of Honest taxpayers $\left(p_{H} \theta w\right)$ and (ii) the voluntary compliance of Evaders on funds not invested offshore $\left(p_{E}\left[1-\phi_{E}\right] \theta w+\right.$ $\left.p_{E} \phi_{E} \theta[w-\omega]\right)$. In the presence of a Scheme it additionally comprises a third component, which is the expected net revenue from the Scheme. Using Propositions 1-3 we obtain

$$
\begin{aligned}
R^{N S}=\theta w- \begin{cases}p_{E} \phi_{E}^{N S} \theta \omega & \text { if } \theta+r-p_{I} \theta[1+f] \leq 0 ; \\
p_{E} \theta \omega-p_{I}\left[p_{E} Q(f, \omega)-c_{A}\right] & \text { if } \theta+r-p_{I} \theta[1+f] \geq 0 ;\end{cases} \\
R^{i}=\theta w- \begin{cases}p_{E} \phi_{E}^{i}\left[\theta \omega-p_{I} s\right] & \text { if }[r+\theta] \omega=p_{I} s ; \\
p_{E}\left[\theta \omega-p_{I} s\right] & \text { if }[r+\theta] \omega>p_{I} s ;\end{cases} \\
R^{u}=\theta w- \begin{cases}p_{E} \phi_{E}^{u}\left\{\theta \omega-p_{I}\left[1-\lambda_{E}^{u}\right] Q(f, \omega)\right\} & \text { if } \theta+r-p_{I} \theta[1+f]=0 ; \\
p_{E}\left\{\theta \omega-p_{I}\left[1-\lambda_{E}^{u}\right] Q(f, \omega)\right\} . & \text { if } \theta+r-p_{I} \theta[1+f]>0 .\end{cases}
\end{aligned}
$$

We can now use the payoffs in (25)-(33) to establish the welfare effects of introducing a Scheme. 
Proposition 4 The introduction of a Scheme never makes the taxpayer worse-off (and can make them better-off). The tax authority is made strictly better-off by introducing an unincentivized Scheme when $\omega>b / r[1+f]$, and is made strictly better-off by introducing an incentivized Scheme when $\theta \omega<s p_{I} /\left[1-\phi_{E}^{i}\right]$. In these cases the introduction of a Scheme leads to a Pareto improvement.

Proposition 4 establishes that both types of taxpayer can never be made worse-off by the introduction of a Scheme, and net revenue to the tax authority may also increase. The proof of Proposition 4 proceeds case-by-case to establish the necessary inequalities. The intuition for the result is straightforward. Honest taxpayers can never be made worse-off as the introduction of a Scheme reduces the probability that they face the burden of being audited (this probability reduces to zero under an incentivized Scheme). Evaders can never be made worse off as by disclosing truthfully under an incentivized Scheme they benefit (i) from being able to avoid the burden associated with being audited by the tax authority and (ii) from the incentivized fine rate. Even under an unincentivized Scheme Evaders can still benefit. First, Evaders face a reduced probability of burdensome audit as they will sometimes disclose truthfully within the Scheme. Second, the introduction of an unincentivized Scheme typically induces Honest taxpayers to invest offshore with a higher probability. This effect is welfare enhancing for Honest taxpayers, but also benefits Evaders by increasing their ability to "hide" among Honest investors. The expected net revenue collected by the tax authority may also increase, for the Scheme enables the tax authority to better discriminate taxpayer type before resorting to an audit. In particular, in an incentivized scheme, the tax authority does not perform any audits in equilibrium. In this way the introduction of a disclosure scheme can lead to a Pareto improvement.

If the introduction of a Scheme leaves the level of offshore evasion unchanged, then a Pareto improvement is assured, for net tax revenue never falls (and typically rises). The introduction of a Scheme can, however, induce changes in offshore investment behavior that lead tax revenue to fall in certain circumstances. Proposition 4 does not guarantee that net revenue will increase when (i) the Scheme is incentivized and the amount invested is sufficiently high $\left(\theta \omega>s p_{I} /\left[1-\phi_{E}^{i}\right]\right)$ and (ii) if $\omega=b / r[1+f]$ and an unincentivized Scheme is implemented. Underlying the possibility that net revenue could fall is that the tax authority is assumed to choose $\hat{f}$ after the evasion decision has been made, and after it has already observed information. The tax authority cannot, therefore, take into account (i) the effects on voluntary compliance of its choice of $\hat{f}$ when it chooses this variable; and (ii) the fact that it will not always get to observe an act of offshore evasion (as $\left.p_{I}<1\right)$.

In the case of an incentivized Scheme with $\theta \omega>s p_{I} /\left[1-\phi_{E}^{i}\right]$ the introduction of the Scheme induces an Evader to switch from investing offshore with a probability $\phi_{E} \in(0,1)$ to instead investing offshore with probability one. In this case net revenue (relative to under No Scheme) is driven down with probability $\left[1-\phi_{E}^{i}\right]$ by the reduction in voluntary compliance of the Evader, but driven up with probability $p_{I}$ by the revenue raised through voluntary disclosure. Recall that the tax authority will only implement an incentivized Scheme when $\theta \omega<s$. This 
condition is not sufficient to guarantee that $\theta \omega>s p_{I} /\left[1-\phi_{E}^{i}\right]$, however, if $p_{I} /\left[1-\phi_{E}^{i}\right]<1$ (i.e., if the likelihood of a revenue increase following from the receipt of information is dominated by the likelihood of a fall in voluntary compliance). Hence, when $p_{I} /\left[1-\phi_{E}^{i}\right]<1$, it is possible that the tax authority will implement a Scheme that ultimately lowers net revenue. The higher is $p_{I}$, therefore, the lower is the risk that a tax authority will implement a Scheme that lowers expected revenue. It is tempting to intuit that the tax authority can never achieve a lower net revenue from implementing an unincentivized Scheme: after all, the fine rate it levies is always then at least as high at that in the absence of a Scheme. In the special case in which $\omega=b / r[1+f]$, however, the introduction of an unincentivized Scheme induces an Honest taxpayer to switch from investing offshore with a probability $\phi_{H} \in(0,1)$ to investing offshore with probability one, which increases the scope for Evaders to hide among Honest investors. Accordingly, we establish in the proof of the Proposition that if Honest taxpayers have a sufficiently low propensity to invest in the absence of a Scheme $\left(\phi_{H}<1-\left[c_{A} r / \theta b\right]\right)$ this effect can lead net revenue to fall upon the introduction of a Scheme.

How reasonable is the assumption that the tax authority has no ability to trade-off the short-term goal of recovering tax on existing offshore investments with the long-term goal of deterring illegal offshore investment in the first place? This question is pertinent as, were

the tax authority assumed to be able to pre-commit to the choice of $\hat{f}$ before the investment decision is made, it would never implement a Scheme that would lead net revenue to fall. A parallel here may be random audit programs, whereby a tax authority must commit to an apparently suboptimal short-run action that potentially entails auditing some low-risk taxpayers in return for improved risk targeting of future audits. We see that some (but by no means all) tax authorities do select a small proportion of audits randomly. Moreover, even those tax authorities that do perform random audits must somehow incentivize tax inspectors to exert equal effort on randomly selected and risk-based audits. Together these two observations seemingly point towards a partial ability to pre-commit that varies across tax authorities. Together these two observations point towards a partial ability to precommit. It is notable, therefore, that even under the most pessimistic assumptions regarding the ability of the tax authority to commit, there are still plausible conditions under which disclosure schemes increase net revenue.

\subsection{Effects on Offshore Investment and Evasion}

What is the effect of introducing a Scheme on the amount of offshore investment? Here it is important to distinguish between all offshore investment (including that made legitimately by Honest taxpayers), and illegal offshore investment (made by Evaders only). Propositions 1 and 3 tell us that Honest taxpayers always invest offshore in the presence of an incentivized Scheme, but not always in its absence. Hence, introducing a Scheme never decreases legitimate offshore investment and may well increase it. Introducing a Scheme will also never decrease offshore evasion and may increase it, in part because the increased investment proclivity of Honest taxpayers offers Evaders better hiding opportunities. These predictions 
are consistent with the empirical finding of Langenmayr (2015) that offshore investment increased following the introduction of the 2009 OVDP in the US. Importantly, however, our model suggests that some or all of the observed increase in offshore investment is from Honest taxpayers who were previously disinclined to invest offshore (because of the possibility of being caught-up in burdensome tax authority investigations). In this light, Langenmayr's finding must be interpreted with caution.

\section{Conclusion}

Tax authorities around the world are using incentivized voluntary disclosure schemes (IOVDS) for the recovery of tax on offshore funds. Such Schemes offer discounts on the regular fine rate for those who voluntarily disclose (albeit in the shadow of the threat of subsequent enforcement). The amounts of revenue being recovered through such Schemes are considerable, and international initiatives such as the OECD Common Reporting Standard are expected to result in the further use of such Schemes. Given these developments, we analyze the optimal design of such Schemes and assess their consequences for tax authorities and for taxpayers.

We consider a dynamic game in which the taxpayer can be Honest (invests offshore legally) or an Evader (invests offshore illegally). We analyze the interaction between a taxpayer and the tax authority when the tax authority may observe the taxpayer's offshore investment with a positive probability. We perform the analysis with and without a voluntary disclosure scheme, and study the comparison. We find that the introduction of a voluntary disclosure schemes can generate a Pareto improvement: honest taxpayers are better able to signal their type, leading to them being less likely to face costly audit, while evaders can benefit from the reduced rate of fine offered within the Scheme. Tax authorities can increase their revenue (net of costs), for revenue derived from voluntary disclose does not require costly audit activity. It is optimal for a tax authority to offer overt incentives for honest disclosure when the cost to an Evader of making a false disclosure is sufficiently high. Offshore investment will increase after the introduction of a Scheme, but this is partly or entirely due to the increase in legitimate such investments by Honest taxpayers. Some judiciousness is still required of tax authorities in the implementation of such Schemes, however. An incentivized Scheme is always gainful to taxpayers, but not always to the tax authority, and the optimal Scheme does not always offer incentives. In particular, unincentivized Schemes are part of an equilibrium strategy when the tax authority cannot make it costly enough for an Evader to disclose falsely, and the offshore evasion gamble is sufficiently attractive.

What design implications does the analysis illuminate that might be important to practitioners in tax authorities? First, the model highlights the importance of a cost asymmetry within the Scheme between making a truthful disclosure and a false disclosure. The evidential requirements surrounding disclosures should be designed to be not unduly burdensome for those who have nothing to hide, but very burdensome for Evaders. Ideally the evidential 
requirements would also have the property of being higher for those with larger hidden investments. In equilibrium, all taxpayers should prefer to make a disclosure in the Scheme, rather than remain outside. Optimal enforcement outside the Scheme is therefore firm enough to ensure this outcome. When the fine rate for accepted disclosures is incentivized, it should be set to the level that is just sufficient that the tax authority fully appropriates the taxpayer's cost of making a false disclosure. Setting the fine rate below this amount does not alter tax behavior, but simply reduces fine revenue.

As no detailed theoretical analysis of IOVDS exists, we note that our study represents a first step and offer the following suggestions for future research. One extension would be to introduce risk aversion. This would require the use of simulation methods, or the simplification of other aspects of the model, however. A second possible extension would be to allow for the possible sheltering of interest in offshore accounts, alongside the possibility that the source capital may also be untaxed. Third, imperfect audit technology might be allowed for, as in Rablen (2014). Last, communication between affected taxpayers through a network, as in Hashimzade et al. (2014), might be introduced. Each of these avenues would enrich the modelling and potentially provides new insights for those in tax authorities who design such Schemes.

\section{References}

Alm, J. and Beck, W. (1993). "Tax amnesties and compliance in the long run: A time series analysis", National Tax Journal 46(1): 53-60.

Alm, J., McKee, M. and Beck, W. (1990). "Amazing grace: Tax amnesties and compliance", National Tax Journal 43(1): 23-37.

Andreoni, J. (1991). "The desirability of a permanent tax amnesty", Journal of Public Economics 45(2): 143-159.

Bazart, C., Beaud, M. and Dubois, D. (2014). "On the efficiency of whistleblowing-based audit schemes to fight tax evasion: An experimental approach", Paper presented at the International Tax Analysis Conference, London.

Bigio, S. and Zilberman, E. (2011). "Optimal self-employment income tax enforcement", Journal of Public Economics 95(9-10): 1021-1035.

Becker, G.S. (1968). "Crime and punishment: an economic approach", Journal of Political Economy 76(2): 169-217.

Boesler, M. (2012). The Controversial 'Lagarde List' Has Leaked, and It's Bad News for the Greek Prime Minister, Business Insider, New York: Business Insider Inc. Available: http://www.businessinsider.com. 
Bordignon, M. (1993). "A fairness approach to income tax evasion", Journal of Public Economics 52(3): 345-362.

Center for Public Integrity (2013). Secrecy for Sale: Inside the Global Offshore Money Maze, Washington: Center for Public Integrity.

Chetty, R., Looney, A. and Kroft, K. (2009). "Salience and taxation: Theory and evidence", American Economic Review 99(4): 1145-1177.

Chu, C.Y.C. (1990). "Plea bargaining with the IRS", Journal of Public Economics 41(3): $319-333$.

Committee of Public Accounts (2008). HMRC: Tackling the Hidden Economy, HC 712, London: The Stationery Office.

Davis, J.S., Hecht, G. and Perkins, J.D. (2003). "Social behaviors, enforcement and tax compliance dynamics" Accounting Review 78(1): 39-69.

Erard, B. and Feinstein, J.S. (1994). "Honesty and evasion in the tax compliance game", RAND Journal of Economics 25(1): 1-19.

European Union (2003). "Council Directive 2003/48/EC of 3 June 2003 on taxation of savings income in the form of interest payments", Official Journal of the European Union L157: 3848.

Feess, E. and Heesen, E. (2002). "Self-reporting and ex post asymmetric information", Journal of Economics 77(2): 141-153.

Feess, E. and Walzl, M. (2005). "Optimal self-reporting schemes with multiple stages and option values", International Tax and Public Finance 12(3): 265-279.

Franzoni, L.A. (2000). "Amnesties, settlements and optimal tax enforcement", Economica 67: $153-176$.

GAO (2013). Offshore Tax Evasion: IRS has Collected Billions of Dollars, but May be Missing Continued Evasion, GAO-13-318, Washington: Government Accountability Office.

Glen Ueng, K.L. and Yang, C.C. (2001). "Plea bargaining with the IRS: extensions and further results", Journal of Public Economics 81(1): 83-98.

Graetz, M.J., Reinganum, J.F. and Wilde, L.L. (1986). "The tax compliance game: Toward an interactive theory of law enforcement", Journal of Law, Economics, and Organization 2(1): $1-32$.

Gravelle, J.G. (2009). "Tax havens: International tax avoidance and evasion", National Tax Journal 62(4): 727-753. 
Hashimzade, N., Myles, G.D., Page, F. and Rablen, M.D. (2014). "Social networks and occupational choice: The endogenous formation of attitudes and beliefs about tax compliance" Journal of Economic Psychology 40: 134-146.

Helm, R.W. (1997). "Offshore investment funds". In: Kirsch, C.E. (Ed.) The Financial Services Revolution: Understanding the Changing Role of Banks, Mutual Funds, and Insurance Companies, Ch. 17, Irwin: Chicago.

HMRC (2006). HMRC Annual Report 2005-06, London: HMRC.

HMRC (2012). Penalties for Inaccuracies in Returns and Documents, CC/FS7, London: HMRC.

Hokamp, S. and Pickhardt, M. (2010). "Income tax evasion in a society of heterogeneous agents - evidence from an agent-based model", International Economic Journal 24(4): 541553.

Johannesen, N. and Zucman, G. (2014). "The end of bank secrecy? An evaluation of the G20 tax haven crackdown", American Economic Journal: Economic Policy 6(1): 65-91.

Kaplow, L. and Shavell, S. (1994). "Optimal law enforcement with self-reporting of behavior", Journal of Political Economy 102(3): 583-606.

Kim, W. and Wei, S.-J. (2002). "Offshore investment funds: monsters in emerging markets?", Journal of Development Economics 68(1): 205-224.

Kolm, S. -C. (1973). "A note on optimum tax evasion", Journal of Public Economics 2(3): 265-270.

Krishna, A. and Slemrod, J. (2003). "Behavioral public finance: Tax design as price presentation", International Tax and Public Finance 10(2): 189-203.

Langenmayr, D. (2015). "Voluntary disclosure of evaded taxes - increasing revenues, or increasing incentives to evade?", CESifo Working Paper No. 5349.

Macho-Stadler, I., Olivella, P. and Perez-Castrillo, D. (1993). "Tax Amnesties in a dynamic model of tax evasion", Journal of Public Economic Theory 1(4): 439-463.

Macho-Stadler, I. and Pérez-Castrillo, J.D. (2002). "Auditing with signals", Economica 69(273): 1-20.

Malik, A.S. and Schwab, R.M. (1991). "The economics of tax amnesties", Journal of Public Economics 46(1): 29-49.

Mealem, Y., Tobol, Y. and Yaniv, G. (2010). "Whistle-blowers as a deterrent to tax evasion", Public Finance Review 38(3): 306-320. 
Melumad, N.D. and Mookherjee, D. (1989). "Delegation as commitment: the case of income tax audits", Rand Journal of Economics 20(2): 139-163.

Oates, J. (2008). HMRC Pays Criminal for 'Tax Dodger' Discs, The Register, London: Situation Publishing. Available: http://www.theregister.co.uk.

OECD (2010). Offshore Voluntary Disclosure: Comparative Analysis, Guidance and Policy Advice, Paris: Organisation for Economic Co-operation and Development.

OECD (2013). Standard for Automatic Exchange of Financial Account Information: Common Reporting Standard, Paris: Organisation for Economic Co-operation and Development.

O'Reilly, R. (2007). "Complete guide to offshore bank accounts for funding online casino and poker play", Blackjack Forum 26(1).

Pfisterer, V.M. (2013). "Walking a fine line - A contextual perspective on the purchase of "stolen" banking data by German authorities", German Law Review 14(7): 926-948.

Pritchard, D. and Khan, N. (2005). "Offshore compliance: Using regression and risk modeling to select cases from large datasets", Paper presented at the IRS Research Conference, June, Washington D.C.

Rablen, M.D. (2010). "Tax Evasion and exchange equity: A reference-dependent approach", Public Finance Review 38(3): 282-305.

Rablen, M.D. (2014). "Audit probability versus effectiveness: The Beckerian approach revisited", Journal of Public Economic Theory 16(2): 322-342.

Reinganum, J. and Wilde, L. (1986). "Equilibrium verification and reporting policies in a model of tax compliance", International Economic Review 27(3): 739-760.

Scotchmer, S. (1987). "Audit classes and tax enforcement policy", American Economic Review 77(2): 229-233.

Stella, P. (1991). "An economic analysis of tax amnesties", Journal of Public Economics 46(3): 383-400.

Treasury Committee (2012). Closing the Tax Gap: HMRC's Record at Ensuring Tax Compliance, HC 1371, London: The Stationery Office.

Watt, H., Winnett, R. and Newell, C. (2012). HSBC Investigation: Clients of Britain's Biggest Bank Exposed, The Telegraph, 10 ${ }^{\text {th }}$ November, London: Telegraph Media Group. Available: http://www.telegraph.co.uk.

Yaniv, G. (2001). "Revenge, tax informing, and the optimal bounty", Journal of Public Economic Theory 3(2): 225-233. 
Yitzhaki, S. (1974). "A note on income tax evasion: a theoretical analysis", Journal of Public Economics 3(2): 201-202.

Zucman, G. (2013). "The missing wealth of nations: Are Europe and the U.S. net debtors or net creditors?", Quarterly Journal of Economics 128(3): 1321-1364. 


\section{Appendix}

Proof of Proposition 4 Beginning with an Evader, first suppose the equilibrium described in part (a) of Proposition 1 holds then, from (25), an Evader's payoff is $C_{E}^{N S}=[1-\theta] w$ in the absence of a Scheme. An Evader can guarantee at least this payoff in the presence of a Scheme by choosing not to invest offshore so is never made worse-off by the introduction of a Scheme. Second, suppose the equilibrium described in part (b) of Proposition 1 holds, in which case the introduction of an unincentivized Scheme reduces the expected consumption loss due to tax authority enforcement from $p_{I}[b+Q(f, \omega)]$ to $p_{I} \alpha_{\mathrm{IN}}^{u}[b+Q(f, \omega)]$, where $\alpha_{\mathrm{IN}}^{u} \in[0,1]$. Finally, the introduction of an incentivized Scheme reduces the expected consumption loss due to tax authority enforcement from $p_{I}[b+Q(f, \omega)]$ to $p_{I} s$. Hence an Evader can never be worse-off following the introduction of a Scheme.

We now consider an Honest taxpayer. Suppose the equilibrium described in part (a) of Proposition 1 holds then the introduction of an incentivized Scheme eliminates the expected consumption loss of $p_{I} \alpha b$ due to tax authority enforcement. The introduction of an unincentivized Scheme (which can only occur if $\theta+r-p_{I} \theta[1+f] \geq 0$ ) increases an Honest taxpayer's payoff if and only if $\alpha>\alpha_{\mathrm{IN}}^{u}$, a condition which necessarily holds as $\alpha=[r+\theta] \omega /[b+Q(f, \omega)] p_{I} \geq Q(f, \omega) /[b+Q(f, \omega)]>[Q(f, \omega)-s] /[b+Q(\bar{f}, \omega)]=\alpha_{\mathrm{IN}}^{u}$. Finally, suppose the equilibrium described in part (b) of Proposition 1 holds then an Honest taxpayer's payoff in the absence of a Scheme, $[1-\theta] w+r \omega-p_{I} b$, is at least weakly exceeded by the payoff $[1-\theta] w+r \omega-p_{I} \alpha_{\mathrm{IN}}^{u} b$ obtained the presence of an unincentivized Scheme, and by the payoff $[1-\theta] w+r \omega$ obtained the presence of an incentivized Scheme. Hence, an Honest taxpayer can never be worse-off following the introduction of a Scheme.

Now consider the tax authority. First suppose the equilibrium described in part (a) of Proposition 1 holds. If an incentivized Scheme is introduced and $\omega=p_{I} s /[r+\theta]$ then expected revenue satisfies $R^{N S}<\theta w$ in the absence of a Scheme and $R^{i}>\theta w$ in the presence of a Scheme, hence the tax authority is better-off. If $\omega>p_{I} s /[r+\theta]$ then for revenue to increase requires $p_{E} \phi_{E}^{i} \theta \omega>p_{E}[\theta \omega-s]$, or equivalently $\theta \omega<s p_{I} /\left[1-\phi_{E}^{i}\right]$. If an incentivized Scheme is introduced (which can occur only if $\theta+r-p_{I} \theta[1+f] \geq 0$ ) we first prove that $R^{u}>\theta w-p_{H} c_{A} /[1+f]$. We may write

$$
R^{u}=\theta w+\omega p_{E} \phi_{E}^{u}\left\{p_{I} \theta[1+f]\left[1-\lambda_{E}^{u}\right]-\theta\right\} \geq \theta w+\omega p_{E} \phi_{E}^{u}\left\{r-p_{I} \theta[1+f] \lambda_{E}^{u}\right\} .
$$

Substituting for $\lambda_{E}^{u}$ from (20) we obtain

$$
R^{u} \geq \theta w+\omega\left\{p_{E} r \phi_{E}^{u}-p_{I} \theta[1+f] \phi_{H}^{u} p_{H} \frac{c_{A}}{Q(\bar{f}, \omega)-c_{A}}\right\} .
$$

We now establish that, in this case, $r \omega-b \alpha_{\mathrm{IN}}^{u} p_{I}>0$ and so $\phi_{H}^{u}=1$. To see this note that the bound $s \geq Q(\underline{f}, \omega)$ in (11) implies that a solution to $r \omega-b \alpha_{\mathrm{IN}}^{u} p_{I}=0$ must satisfy

$\omega \leq\{b / r[1+\bar{f}]\}\left\{\left[p_{I} \theta[\bar{f}-\underline{f}]-r\right] / \theta\right\}$. Then for $\theta+r-p_{I} \theta[1+f] \geq 0$ we have

$$
\begin{aligned}
\frac{b}{r[1+\bar{f}]}\left[\frac{p_{I} \theta[f-\underline{f}]-r}{\theta}\right] & \leq \frac{b}{r[1+\bar{f}]}\left[\frac{\theta\left\{1-p_{I}[1+\underline{f}]\right\}}{\theta}\right] \\
& \leq \frac{b}{r[1+\bar{f}]} \leq \frac{b}{r[1+f]}
\end{aligned}
$$


But as we must have that $\omega \geq b / r[1+f]$ in the absence of a Scheme, it must be that $r \omega-b \alpha_{\mathrm{IN}}^{u} p_{I}>0$, which implies $\phi_{H}^{u}=1$. Thus (A.1) writes as

$$
R^{u}=\theta w+\omega\left\{p_{E} r \phi_{E}^{u}-p_{I} \theta[1+f] p_{H} \frac{c_{A}}{Q(\bar{f}, \omega)-c_{A}}\right\} .
$$

Then, from Proposition $2, \phi_{E}^{u}>\left[p_{H} / p_{E}\right]\left\{c_{A} /\left[Q(\bar{f}, \omega)-c_{A}\right]\right\}\{Q(f, \omega) /[Q(f, \omega)-s]\}$. Noting also that $Q(f, \omega) /[Q(f, \omega)-s] \geq 1$ we therefore obtain

$$
\begin{aligned}
R^{u} & >\theta w+\omega\left\{p_{E} r \phi_{E}^{u}-p_{I} \theta[1+f] p_{H} \frac{c_{A}}{Q(\bar{f}, \omega)-c_{A}}\right\} \\
& >\theta w+\frac{p_{H} c_{A}}{\theta[1+\bar{f}]}\left\{r-p_{I} \theta[1+f]\right\} \\
& =\theta w-\frac{p_{H} c_{A}}{1+\bar{f}} \geq \theta w-\frac{p_{H} c_{A}}{1+f} .
\end{aligned}
$$

Hence, it is sufficient for expected net revenue to increase when $\omega=b / r[1+f]$ if $\theta w-$ $p_{H} c_{A} /[1+f]>\theta w-p_{E} \phi_{E}^{N S} \theta \omega=\theta w-p_{H} c_{A} \phi_{H}^{N S} \theta \omega /\left[Q(f, \omega)-c_{A}\right]$. This condition holds if and only if $\left[1-\phi_{H}^{N S}\right] Q(f, \omega)<c_{A}$, which is equivalent to $\phi_{H}^{N S}>1-\left[c_{A} r / \theta b\right]$. It is sufficient for expected net revenue to increase when $\omega>b / r[1+f]$ if $\theta w-p_{H} c_{A} /[1+f]>$ $\theta w-p_{E} \phi_{E}^{N S} \theta \omega=\theta w-p_{H} c_{A} \theta \omega /\left[Q(f, \omega)-c_{A}\right]$. This condition holds as $c_{A}>0$.

Now suppose $\theta+r-p_{I} \theta[1+f] \geq 0$ and the equilibrium described in part (b) of Proposition 1 holds. If an unincentivized Scheme is implemented we prove first that $R^{u} \geq$ $\theta w+\theta \omega p_{E}\left\{p_{I}[1+f]-1\right\}$. We must have $\phi_{E}^{u}=\phi_{H}^{u}=1$ for $\phi_{E}^{N S}=\phi_{H}^{N S}=1$ and, from above, the introduction of an unincentivized Scheme never makes offshore investment less attractive to either taxpayer type. Using the definition of $\lambda_{E}^{u}$ in (20) and noting that $c_{A} Q(f, \omega) /\left[Q(\bar{f}, \omega)-c_{A}\right] \geq c_{A} Q(f, \omega) /\left[Q(f, \omega)-c_{A}\right] \geq c_{A}$ we have

$$
\begin{aligned}
\mathbf{E}\left(R^{u}\right) & =\theta w+\theta \omega p_{E} \phi_{E}^{u}\left\{p_{I}[1+f]\left[1-\lambda_{E}^{u}\right]-1\right\} \\
& =\theta w+\theta \omega p_{E}\left\{p_{I}[1+f]-1\right\}-p_{E} p_{I} \lambda_{E}^{u} Q(f, \omega) \\
& =\theta w+\theta \omega p_{E}\left\{p_{I}[1+f]-1\right\}-p_{I} p_{H} \frac{c_{A} Q(f, \omega)}{Q(\bar{f}, \omega)-c_{A}} \\
& \geq \theta w+\theta \omega p_{E}\left\{p_{I}[1+f]-1\right\}-p_{I} p_{H} c_{A} .
\end{aligned}
$$

It is therefore sufficient for expected net revenue to increase following the introduction of an unincentivized Scheme if $\theta w+\theta \omega p_{E}\left\{p_{I}[1+f]-1\right\}-p_{I} p_{H} c_{A}>\theta w+p_{E} \theta \omega\left\{p_{I}[1+f]-\right.$ $1\}-p_{I} c_{A}$, which holds as $p_{H}<1$. If an incentivized Scheme is implemented we must again have $\phi_{E}=\phi_{H}=1$, so offshore evasion is the same under both an incentivized and an unincentivized Scheme (thus we may focus purely on net revenue arising within the Scheme). The tax authority will only implement an incentivized Scheme if the revenue raised within the Scheme is higher than that raised within an unincentivized Scheme. Hence, as an unincentivized Scheme raises net revenue, so must an incentivized Scheme. 


\section{Figures}

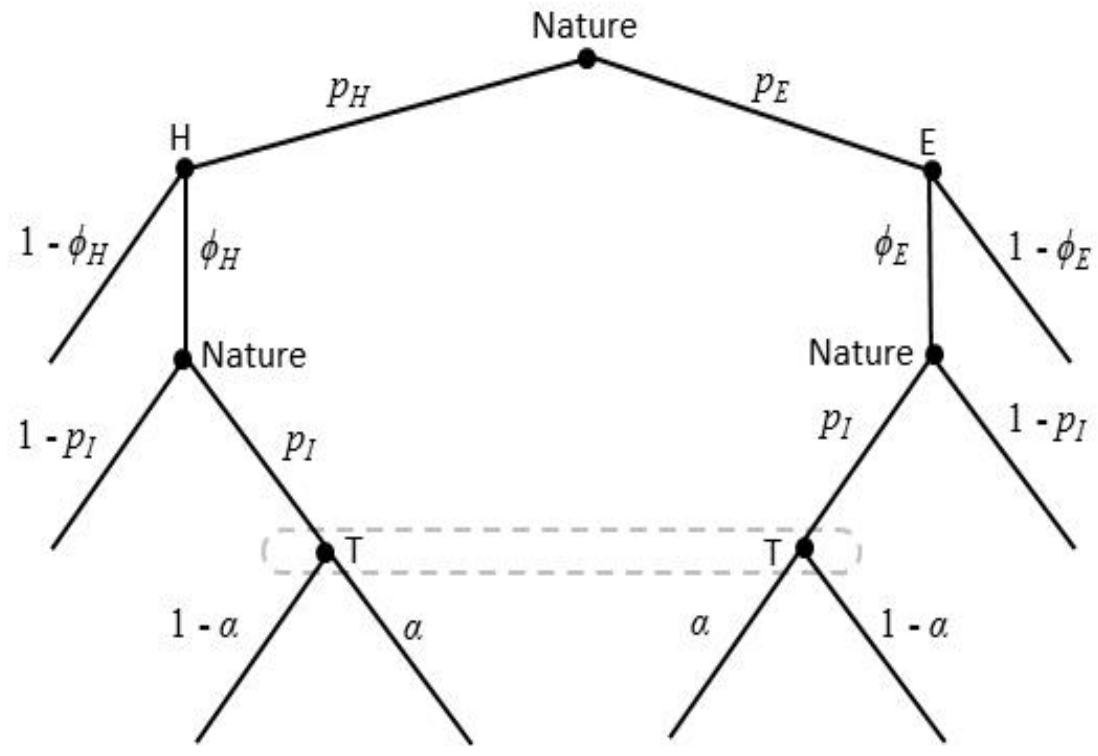

Figure 1: The offshore evasion game in the absence of an IOVDS. 


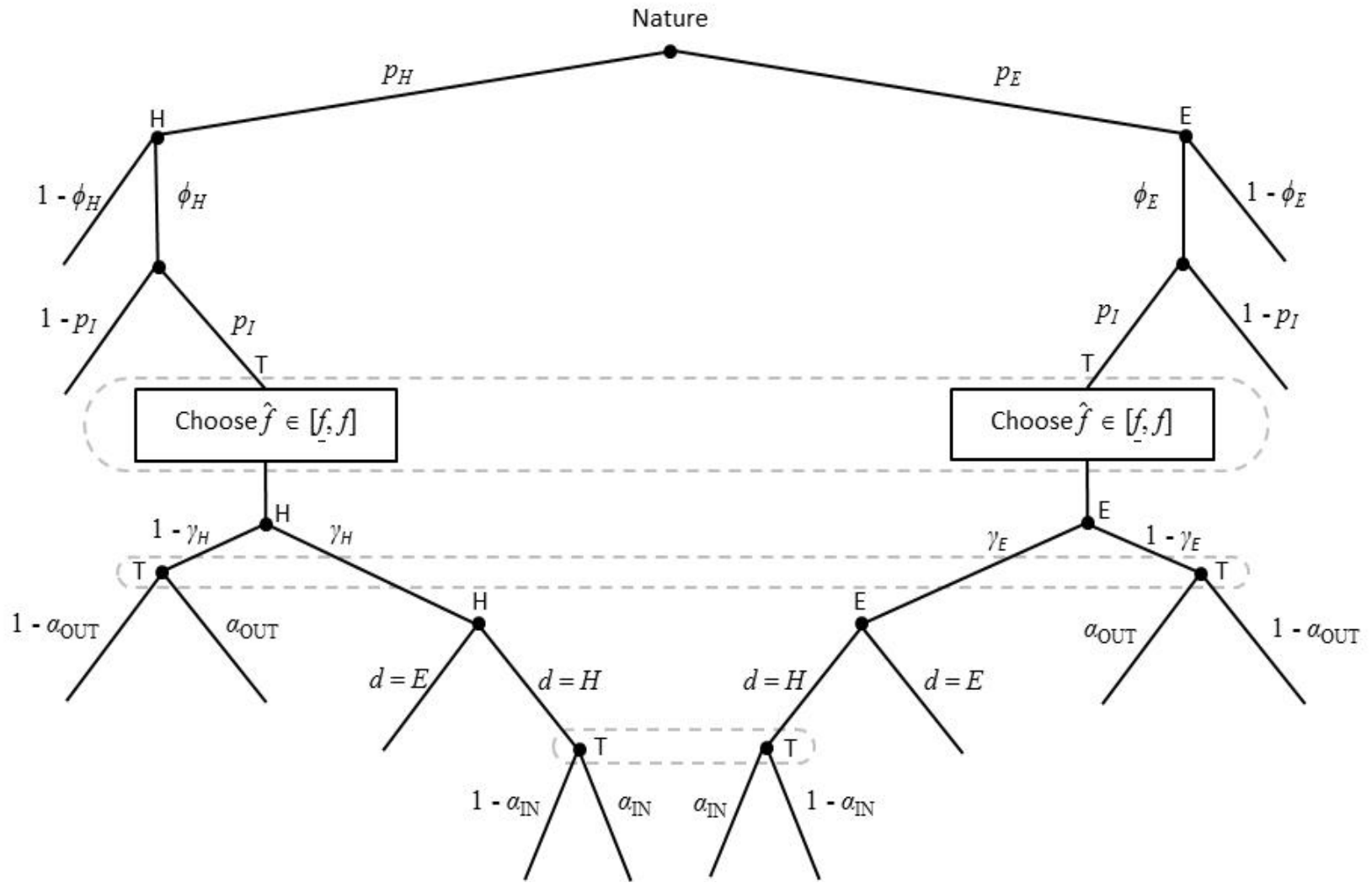

Figure 2: The offshore evasion game in the presence of an IOVDS. 